\title{
HVMANITAS
}

\section{O Arco da Aramenha em Castelo de Vide}

\section{Autor(es): $\quad$ Mantas, Vasco}

Publicado por: Faculdade de Letras da Universidade de Coimbra, Instituto de Estudos

URL

persistente: URI:http://hdl.handle.net/10316.2/8519

DOI: $\quad$ DOI:http://dx.doi.org/10.14195/2183-1718_62_17

Accessed : $\quad$ 26-Apr-2023 14:24:46

A navegação consulta e descarregamento dos títulos inseridos nas Bibliotecas Digitais UC Digitalis, UC Pombalina e UC Impactum, pressupõem a aceitação plena e sem reservas dos Termos e Condições de Uso destas Bibliotecas Digitais, disponíveis em https://digitalis.uc.pt/pt-pt/termos.

Conforme exposto nos referidos Termos e Condições de Uso, o descarregamento de títulos de acesso restrito requer uma licença válida de autorização devendo o utilizador aceder ao(s) documento(s) a partir de um endereço de IP da instituição detentora da supramencionada licença.

Ao utilizador é apenas permitido o descarregamento para uso pessoal, pelo que o emprego do(s) título(s) descarregado(s) para outro fim, designadamente comercial, carece de autorização do respetivo autor ou editor da obra.

Na medida em que todas as obras da UC Digitalis se encontram protegidas pelo Código do Direito de Autor e Direitos Conexos e demais legislação aplicável, toda a cópia, parcial ou total, deste documento, nos casos em que é legalmente admitida, deverá conter ou fazer-se acompanhar por este aviso. 
humanitas

Vol. LXII

2010 


\title{
O ARCO DA ARAMENHA EM CASTELO DE VIDE
}

\author{
Vasco Gil Mantas \\ Universidade de Coimbra
}

\section{Resumo}

A reutilização numa porta da vila de Castelo de Vide de um arco recuperado nas ruínas de S. Salvador de Aramenha levanta algumas questões de natureza arqueológica e cultural. Neste artigo procura-se provar a origem romana do arco da Porta da Aramenha, situando a sua transferência no ambiente da cultura das elites dos inícios do século XVIII.

Palavras-chave: Arco romano; Aramenha; Castelo de Vide; Iluminismo.

\begin{abstract}
The reuse in a gate of Castelo de Vide of an arch recovered from the ruins of S. Salvador de Aramenha raises questions of archaeological and cultural nature. In this paper we attempt to prove the roman origin of the arch at the Porta da Aramenha, placing its transfer in the context of the cultural environment of the beginning of the $18^{\text {th }}$ century.

Key-words: Roman arch, Aramenha, Castelo de Vide, Enlightenment.

A reutilização de monumentos, no todo ou em parte, é uma prática antiquíssima, motivada fundamentalmente por motivos de economia ou por razões de ordem simbólica, mais ou menos relacionada com o imaginário cultural dominante num determinado momento histórico. Voltamos neste artigo a reflectir sobre um dos casos mais interessantes conhecidos em Portugal, o da chamada Porta da Aramenha, em Castelo de Vide, a qual teria sido transferida das ruínas da cidade luso-romana de Ammaia, situadas em S. Salvador de Aramenha, concelho de Marvão, cumprem-se exactamente este ano três séculos. A razão que nos leva a retomar este assunto, acerca
\end{abstract}


do qual a bibliografia, embora não sendo vasta, é concorde quanto à origem romana do arco da Porta da Aramenha, é a aparente dúvida agora suscitada por Armin Stylow a propósito da romanidade da porta, em função da iconografia da mesma. Eis o que o distinto epigrafista alemão escreveu sobre este desaparecido monumento de Castelo de Vide numa recentíssima publicação a propósito de documentação do tempo das Invasões Francesas relacionada com as antiguidades de S. Salvador de Aramenha: A porta foi demolida em 1891 e a inscrição conserva-se na Câmara Municipal de Castelo de Vide. Na verdade, o edifício que aparece como sendo essa porta na foto antiga publicada por Mantas 2000, 419 fig.4 (cf. ibid. 413) detém uns rasgos claramente posteriores (da época barroca?); se, de facto, se trata de uma das portas da Ammaia, deve ter sido amplamente restaurada (Stylow 2009: 40). Stylow refere-se aqui à inscrição setecentista outrora colocada sobre a porta em questão, à qual voltaremos a seu tempo, e à referência que fizemos ao monumento numa comunicação apresentada à Mesa-Redonda Sociedad y Cultura en Lusitania Romana, que teve lugar em Mérida no último ano do milénio passado (Mantas 2000: 413-414, 419).

Embora o comentário de Stylow seja pertinente quanto ao aspecto geral da Porta da Aramenha, julgamos que grande parte dos materiais terá sido realmente recuperada nas ruínas da cidade que no século XVIII se identificava como Medóbriga (Guerra 1996: 7-33), as quais, durante séculos e até há bem poucos anos, forneceram materiais para construções muito diversas, por vezes significativamente afastadas do seu local de origem ${ }^{1}$. Seja como for, cremos que o assunto merece ser retomado, no sentido de tentar precisar até que ponto houve reutilização de materiais romanos na obra da Porta da Aramenha, transformados ou não. Não podemos esquecer dois aspectos importantes desta problemática, que são a construção à antiga, imitando modelos romanos, que esteve tão em voga na época em que a porta foi edificada, assim como a intenção simbólica subjacente a muitas dessas construções numa fase de apogeu da afirmação do estado moderno, evidentemente inspirado pelo passado romano. A reutilização, numa construção do tempo de D. João V, do arco transportado da Aramenha insere-se

1 Não faltam referências, na documentação conhecida, à reutilização de materiais extraídos das ruínas da Aramenha, nomeadamente na edificação da Sé de Portalegre e até por altura da renovação da estrada Portalegre-Castelo de Vide. Agradecemos cordialmente o apoio da Sociedade Martins Sarmento, do Doutor Jorge de Oliveira (UE) e do Dr. Luís Madeira (FLUC), que preparou as ilustrações para publicação. 
perfeitamente nesta lógica de identificação, ao gosto dos responsáveis políticos do estado centralizado e absolutista.

Começa hoje a ser preciso algum esforço para compreender o fenómeno, que a formação das elites da época assentava sobretudo na cultura humanista, ainda que filtrada ou curiosamente associada à componente religiosa, fosse ela católica ou protestante. Naturalmente, o legado romano constituía o elemento principal dessa formação, resultando com frequência por parte das classes cultas uma vontade de ver como romano o que realmente nunca o foi, como aconteceu tantas vezes, por exemplo, com as pontes. $\mathrm{O}$ interesse pelos monumentos romanos levou muitas vezes à sua transferência, total ou parcial, ou à criação de falsas ruínas, por vezes incluindo um ou outro elemento autêntico (Choay 2009: 65-101). Apenas a título de exemplo lembramos o projecto, felizmente não concretizado, de transferir a Maison Carrée de Nîmes para Versalhes, as ruínas nos jardins do palácio imperial de Schönbrunn, em Viena de Áustria, ou o Hornito de Santa Eulália, em Mérida.

Esta característica da cultura dos séculos que correspondem à Época Moderna reflecte-se com muita frequência, de forma que podemos considerar normal e sem intenção que se afaste da reflexão própria de gente instruída, nos relatos de viagem da época, quer se trate de civis ou de militares. Assim aconteceu com o texto agora divulgado por Armin Stylow, extraído do diário redigido em 1810 por um oficial britânico, empenhado nas campanhas da Guerra Peninsular, o Coronel Alexander Dickson (Stylow 2009: 37-38). Eis o que nos interessa em relação ao arco de Aramenha: The gate by which we entered is called the gate of Aramenha, and has a inscription over it, stating that in the year 1710, the whole gate was brought from the ruins of the ancient city of Meidobriga, about a league from this, where it stood, by order of the then Governor of Castello de Vide, and re-erected as a gate on the fortifications of the place, being the entrance from the Spanish frontier and the side of Portalegre. The gateway is of large squared stones rough cut, is of massive construction, not high, but nevertheless handsome, evidently Roman, and is a perfect specimen of antiquity (Leslie 1905: 160). Ainda que esta breve alusão às características construtivas da porta não possa resolver de forma inquestionável a questão da origem romana do monumento não pode deixar de ser tomada em conta, tanto mais que o seu autor conhecia bem as fortificações da época e a referência que fez ao talhe dos blocos concorda com o que ainda hoje se pode ver no local das ruínas de S. Salvador de Aramenha. Como acontece noutros casos, tal como o do arco romano junto 
à Porta de Belcouce, em Coimbra (Mantas 1992: 502-504), não temos, pelo menos que conheçamos, outra descrição da Porta da Aramenha. Cumpre aqui sublinhar que na narrativa do Coronel Dickson, oficial de Artilharia habituado ao rigor dos cálculos matemáticos, nada encontramos que se aproxime das descrições delirantes que nos foram transmitidas noutras situações, como sucedeu, por exemplo, com o discutido arco romano da Praça do Giraldo, em Évora ${ }^{2}$. Pena foi que José Cornide não tivesse oportunidade de passar por Castelo Vide, por falta de tempo, limitando-se a reconhecer que, ao contrário de Marvão, a vila não possuía uma posição militar favorável. Cornide, que conhecia muito bem as antiguidades romanas, não deixaria de acrescentar alguma coisa válida aos testemunhos sobre o arco da Porta da Aramenha, como fez a propósito de muitas outras antigualhas nos seus relatos de viagens por Espanha e Portugal (Abascal / Cebrián 2009: 671).

Da Porta da Aramenha, todavia, possuímos documentação iconográfica, não muito rica, mas suficiente para alimentar uma análise coerente da arqui-

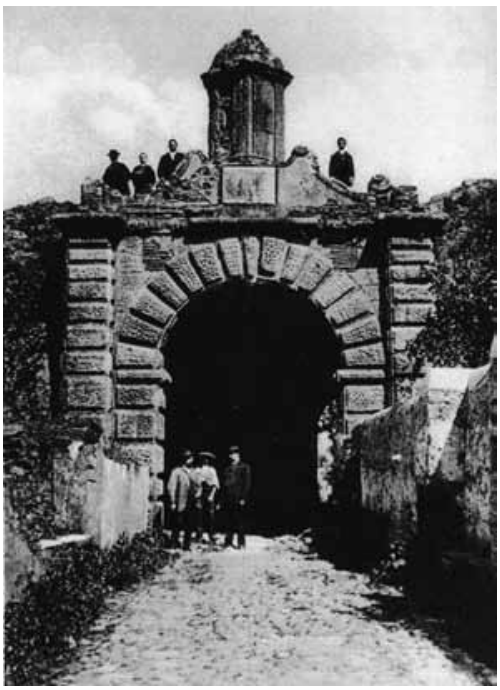

Fig.1. A Porta da Aramenha, cerca de 1890 (Segundo postal de Martins e Silva, Lisboa, 1904). tectura do monumento e daquilo que nele pode ser de origem romana. Referimonos, naturalmente, a uma fotografia de autor desconhecido, reproduzida com alguma frequência a partir de um postal ilustrado dos primeiros anos do século $\mathrm{XX}$, e que remonta aos últimos tempos do monumento, talvez mesmo quando já se planeava a demolição da estrutura, em 1890. A partir desta fotografia, que mostra completamente a porta (Fig.1), encimada por uma guarita típica das fortificações do século XVIII, foi feita uma gravura que mostra apenas a parte inferior do monumento, restringindo-se ao que se considerava obra romana, gravura da autoria de Guilherme Gameiro, desenhador do então Museu Etnológico

2 A inexistência de tal arco, que segundo alguns teria dezenas de colunas e de estátuas (!), foi definitivamente demonstrada por Francisco Bilou, na sua excelente dissertação de Mestrado intitulada A (Re)fundação do Aqueduto da Água da Prata em Évora (1535-1537). Novos dados arqueológicos, defendida em Novembro de 2009 na Universidade de Évora. 
Português, reproduzida por Leite de Vasconcelos (Vasconcelos 1913: 179180). Mais tarde, em 1917, num dos primeiros artigos publicados sobre arcos romanos em Portugal, Vergílio Correia refere brevemente o arco da Porta da Aramenha, publicando a fotografia a que aludimos (Correia 1972: 224)³. Não há dúvidas quanto ao facto de a fotografia e de a gravura representarem o mesmo monumento, ainda que possamos admitir ter existido outra fotografia, a partir da qual teria sido executada a figura que

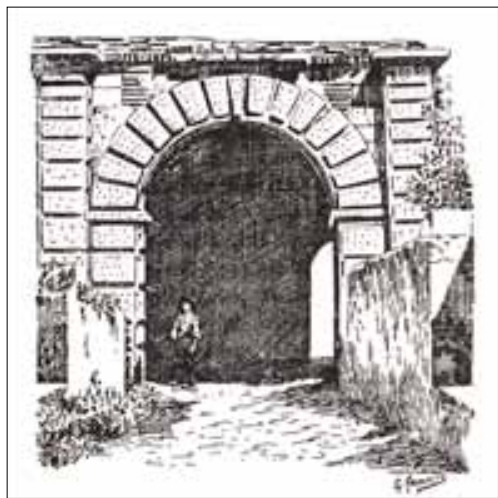

Fig.2. Pormenor da Porta da Aramenha (Gravura de Guilherme Gameiro). mereceu o comentário crítico de Stylow. Todavia, cremos possível tratar-se simplesmente de uma simplificação na qual se eliminou tudo o que não era garantidamente antigo, inclusive a inscrição de 1710, reduzindo a uma as pessoas que povoam a fotografia, aliás figura semelhante a uma das que estão presentes no documento fotográfico (Fig.2).

De tudo o que lá está sobreviveu apenas a inscrição setecentista, hoje conservada na Secção de Arqueologia da Câmara Municipal de Castelo de Vide. É uma placa em mármore, com 97 x 72 centímetros, contendo um texto ocupando um campo epigráfico ligeiramente moldurado, letreiro de cuidada gravação e cuja análise não deixa de ter interesse para o problema que nos ocupa (Fig.3). Eis o conteúdo da epígrafe, que lemos no original: Reynando em Portugal / o muyto alto e poderozo senhor / dom Ioão o Quinto / foi este portado tirado / debaixo das antiguas ruinas / da cidade de Medobriga / fundada 1906 annos antes de Xpto / no sitio chamado Aramenha / transferido e posto neste lugar / por Manoel de Azevedo Fortes / Governador desta Praça / no anno de Xpto de 1710. A placa vê-se perfeitamente na fotografia

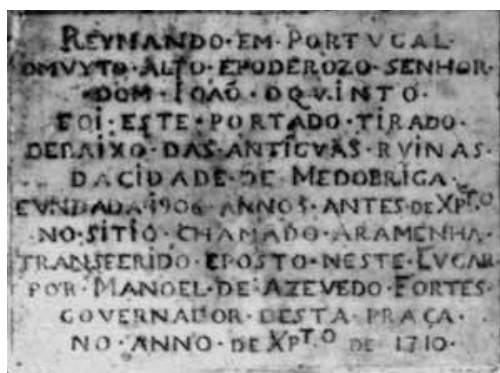

Fig.3. A inscrição da porta comemorando a transferência do arco em 1710 .

3 Na reedição do artigo, publicado em 1917 (Terra Portuguesa, 3: 38-41), não foi inserida a fotografia do arco. 
que ficou da Porta da Aramenha e pode servir de escala para calcular as dimensões do arco, como veremos.

A identificação das ruínas de Aramenha como Medóbriga é perfeitamente normal, reflectindo a erudição da época, que situava a referida cidade nas ruínas vizinhas de Marvão, enquanto atribuía a Portalegre a sucessão da Ammaia luso-romana, de acordo com a opinião de Frei Amador Arrais, timidamente contestada por alguns (Arrais 1974: 241-242; Sotto Mayor 1984: 35). Para elaborar esta tese, o prelado apoiou-se na epígrafe honorífica de Lúcio Vero (IRCP 616), achada numa ermida dos arredores de Portalegre, onde se referem claramente os Municipes Ammaienses. Na verdade, este facto apenas confirma, eventualmente, a deslocação de materiais da Aramenha para reutilização noutros locais, não faltando testemunhos da preservação de inscrições em edifícios de culto, mais ou menos afastados da origem das pedras ${ }^{4}$.

Eis o que, pouco tempo antes da visita do Coronel Dickson a Castelo de Vide, escreveu, em 1804, Francisco do Nascimento Silveira: Meidobriga. Desta povoação se lembra Plínio, chamando Plumbarios aos seus habitadores. Esteve ela situada sobre o rio Sever, nas raizes do monte Herminio Menor. Crê o bispo Arraes, que ela tivera belos, e sumptuosos edifícios, colunas, e sepulcros com elegantes inscrições, aquedutos e medalhas, que ele examinou (Silveira 1804: 280-282). Serve este exemplo para recordar o tipo de informação de que, ao tempo, dispunha o viajante culto para interpretar a geografia antiga e as ruínas com que topava pelo caminho (Mantas 2009: 89-109), enquanto, muitas vezes de forma involuntária, contribuía através de novos achados ou de simples comentários para o progresso do conhecimento histórico ou, como no caso que agora nos interessa, para nos transmitir a memória da um monumento desaparecido.

De que houve transferência de um arco da Aramenha para Castelo de Vide não é possível duvidar. Com efeito, o pároco local, ao responder ao célebre inquérito de 1758, escreveu o seguinte: Haverá trinta e oito annos que deste citio levaram para a villa de Castello de Vide hum grande portado de cantaria bem lavrado que mostrava ser o principal da dita Cidade, o qual puzeram na porta principal que de novo se fés para a dita villa e fica

4 As epígrafes indicam, por vezes, a presença de um sítio romano coincidente com o local da reutilização, como na ermida de Nossa Senhora de Entre-Águas (CIL II 165=IRCP 459), perto de Avis. Noutros casos, como sucedeu com as inscrições de Bobadela colocadas na capela de Coito de Midões (CIL II 401-402), a transferência fez-se para mais longe. 
para a parte do sul, e se chama a Porta da Aramenha (Gorjão / Machado 1993: 58; Videira 2008: 36-37). Este testemunho poderia ser considerado decisivo, se não houvesse outros, mas não podemos esquecer que muitas das respostas ao inquérito enfermam de descrições ou referências fantasistas ou contaminadas por interpretações eruditas. O pároco de $\mathrm{S}$. Salvador de Aramenha poderia ter lido a inscrição sobre a porta, em Castelo de Vide, o que certamente fez, levando-o a acrescentar o apontamento em questão, embora a data indicada não corresponda à data oficial da transferência do arco, que levou a mudar o nome da porta de Porta do Arco para Porta da Aramenha, o que também é relevante. Se um dia houver oportunidade de recuperar alguns dos blocos da porta, parte dos quais reutilizados num cais de carga nos arredores de Castelo de Vide, será possível, através de uma análise petrográfica, determinar se têm a mesma origem que as subsistentes na Aramenha, o que pode não servir para outra coisa a não ser estabelecer uma pedreira comum para os materiais em causa, o que, ainda assim, contribuiria para fortalecer a tese da transferência.

Voltemos à análise da Porta da Aramenha. O seu aspecto geral é, indiscutivelmente, o das portas monumentais típicas da arquitectura militar do século XVIII, de acordo com a data indicada na lápida que ostentava. Antes de nos ocuparmos da figura do construtor e do contexto que viu nascer a obra, que nos parece particularmente importante para explicar a transferência da porta, tentemos discernir entre o que pode ser romano e o que corresponde aos trabalhos ordenados por Manuel de Azevedo Fortes. Para tal, o melhor meio disponível é o recurso à observação das duas imagens que se conhece, uma das quais, como dissemos, foi realizada, aparentemente, a partir da conhecida fotografia que mostra a porta na totalidade. Antes de mais, devemos considerar que os materiais reutilizados foram retocados, de forma a garantir uniformidade ao conjunto, disfarçando o que poderia ser mais facilmente reconhecido como trabalho antigo. Considerando o monumento no seu todo, cremos que apenas as aduelas do arco, ou pouco mais, terão sido trazidas das ruínas da Aramenha.

A expressão que se encontra na epígrafe da porta, tirado de baixo das antiguas ruínas, sugere que o arco não se encontrava visível, ou pelo menos, completamente visível, obrigando a sua recuperação a trabalhos de escavação, o que contraria o teor de um documento que referiremos adiante. Outra hipótese que poderíamos considerar, aliás verificada na Aramenha com a Ponte da Portagem, reconstruída em grande parte com materiais da ponte romana outrora existente junto às ruínas da cidade 
(Oliveira 1992: 121-130), seria o da inscrição se referir simbolicamente ao arco, cuja romanidade consistiria apenas no facto de ter sido construído com materiais trazidos da Aramenha. Não nos custa admitir que a pedra para a construção da porta, sobretudo os silhares profusamente presentes na construção, tenham sido extraídos das ruínas. Esta circunstância, apesar de merecer alguma atenção, tanto mais que, como é sabido e documentado, as ruínas serviram longamente de pedreira, não pode ser considerada tendo em conta o que sobre a transferência do arco escreveu o próprio Manuel de Azevedo Fortes: Certifico que, encarregando-me Sua Magestade, que Deus Guarde, a reedificação d'esta praça, que os inimigos deixaram demolida, $e$ sendo necessário fazer-se uma nova porta na cortina de S. Francisco, por estar de todo incapaz a que chamavam do carro, me vali de um portado de cantaria grossa e fortissima, que ficou inteiro entre as ruínas da antiga cidade de Medobriga, aonde chamam Aramenha, uma legoa desta villa, e estava servindo de portico e entrada a uma quinta que n'aquelle sitio tem Luiz Freire da Fonseca Coutinho, o qual sabendo o meu intento, e que desejava servir-me do dito portado para a fortificação desta praça, querendo-lho comprar, o offereceu gratuitamente para o serviço de Sua Magestade, sacrificando a este fim o gosto que tinha em conservar na sua quinta aquella antiguidade e memoria, pois foi fundada a dita cidade, segundo os historiadores, mil e novecentos e seis annos, antes da vinda de Christo. E com effeito, mandei conduzir o dito portado para esta praça, para se collocar na nova porta de Aramenha, e com elle se poupou á fazenda real, só no arranco e lavor das pedras, se se houvessem de fazer, mais de duzentos mil réis. Passa o referido na verdade pelo juramento dos Santos Evangelhos, de que mandei passar o presente por mim assignado. Castello de Vide 15 de novembro de 1710 (Gusmão 1861: 394; Oliveira 2005: I, VIII $)^{5}$. Perante tal testemunho não podemos duvidar da transferência do arco, defendida sob o pretexto da economia, aqui invocada para salvar um monumento da Antiguidade, o que reflecte bem a personalidade de quem assumiu a iniciativa da proposta. Infelizmente, as consequências da reutilização acabaram por se revelar desastrosas.

Uma cuidada observação das representações da porta e a sua comparação com alguns pormenores específicos de outros monumentos semelhantes confirmam o que nos diz o documento citado acima, repetida de forma

5 O documento em questão faz parte do espólio da $\operatorname{Dr}^{\mathrm{a}}$ Delmira Maçãs, grande proprietária da região, falecida em 2007. 
abreviada na epígrafe colocada no monumento. Infelizmente não existe nenhuma figura do lado interior da Porta da Aramenha, embora uma planta da autoria de José Mansos de Faria, copiada em 1865 por Bon de Sousa e conservada na Direcção de Infra-Estruturas do Exército (Faria 1865), mostre tratar-se do tipo normal, com uma passagem abobodada entre as duas faces da muralha. A referida planta não contém a indicação da escala mas permite verificar que o arco exterior tem a mesma largura na base que $o$ arco interior. Esta coincidência não obriga a que os arcos fossem de idêntica construção, como a simples análise dos que existem noutras fortificações da mesma época imediatamente demonstra. Existe, todavia, um pormenor que nos parece significativo, que é o do corte e número das aduelas presentes no arco exterior da Porta da Aramenha. Com efeito, os documentos iconográficos da porta permitem, sem problemas, contar o número de aduelas empregues no arco a partir da cornija. São, no total, contando a do fecho, um pouco menor, 15 blocos, número aproximado do que se conta em arcos reconhecidamente romanos e de maiores dimensões, como a chamada Porta de Évora, em Beja, ou o arco do forum de Bobadela ${ }^{6}$. O talhe dos silhares, pelo contrário, não se conforma com o que normalmente corresponde ao das aduelas de portadas construídas de raíz, no século XVIII, mesmo quando imitam vagamente obra antiga. Tomemos como exemplo a muito sóbria Porta de Évora (Fig.4), das fortificações modernas de Estremoz, contruída no início do século XVIII e que é, tipologicamente, uma das que mais se aproxima da Porta da Aramenha. Embora estejam presentes as pilastras rusticadas ladeando o arco, como em Castelo de Vide, verifica-se que

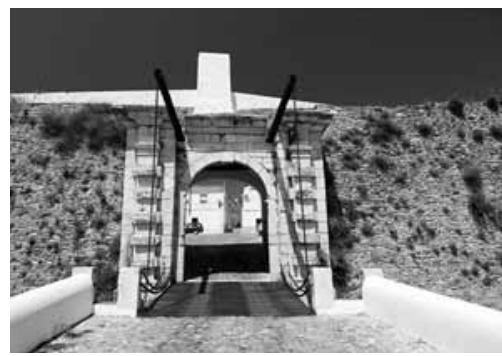

Fig.4. A Porta de Évora, na cidade de Estremoz (Foto de Dias dos Reis). o arco conta apenas com nove aduelas, estreitas e longas, muito diferentes do que existiu na Porta da Aramenha. Considerando as diferenças entre as portas de Santa Catarina, de Santo António e dos Currais, em Estremoz (Espanca 1969: 65-85), e a Porta de Évora, praticamente contemporânea

6 Os arcos de construção romana contam, de maneira geral, com um número de aduelas superior ao que se encontra no mesmo tipo de estruturas de épocas mais recentes. $\mathrm{O}$ arco da Porta de Évora, em Beja, e o arco do forum, em Bobadela, contam com 17 aduelas cada. 
do edifício de Castelo de Vide, julgamos muito significativas quer as referidas diferenças, quer o ar de família que a Porta de Évora e a Porta da Aramenha reflectem, valorizando desta forma a desigualdade ostentada no corte e número das aduelas dos arcos destes dois monumentos militares. Cremos, portanto, que as aduelas do arco exterior da Porta da Aramenha são realmente romanas, ainda que trabalhadas a picotado, prática vulgar nos séculos XVII e XVIII, tal como foi feito em toda a silharia do monumento.

Vejamos agora a questão das dimensões do arco. Não conseguimos identificar, por ora, nenhuma planta com indicação das dimensões do arco, pelo que nos resta, como alternativa, utilizar como escala a placa da inscrição presente na fotografia da Porta da Aramenha. Este exercício, que já foi tentado anteriormente (Pereira 2009: 142), permite algum rigor no cálculo, que seria aleatório se tivessemos que recorrer apenas às figuras humanas junto da porta. Como sabemos que a inscrição tem 97 centímetros de comprimento podemos atribuir ao arco uma largura de cerca de 3,30 metros, ou seja, em termos de metrologia romana, o equivalente a 11 pés. Voltando a repetir a operação, agora para a altura do arco até ao fecho, teremos uns $4,90 \mathrm{~m}$, perto de 16 pés romanos. É claro que estas medidas são apenas aproximadas e só a descoberta de um desenho ou planta cotada da Porta da Aramenha poderá resolver o problema. A própria utilização como escala da placa epigrafada que se conservou exige cautela, considerando a existência de vários planos na imagem em que ela aparece representada.

Toda esta aritmética tem que ver com uma questão ainda mais complicada, embora de alguma forma até agora considerada resolvida, que é a do local de origem do arco nas ruínas, sempre, ou quase sempre, atribuído à chamada Porta Sul da muralha de Ammaia. Ora esta atribuição consensual não passa sem algumas pequenas dificuldades. Na verdade, considerando que a largura do arco pouco ultrapassava os três metros sucede que o espaço disponível entre as torres da Porta Sul é excessivamente grande, pois atinge 6,50 metros. Esta medida só pode ser aceite se considerarmos como também fazendo parte da porta da muralha amaiense as pilastras que enquadravam a Porta da Aramenha, o que nos parece inaceitável. Devemos desistir de tentar identificar o local de onde se retirou o arco, ou podemos simplesmente aceitar a tese da Porta Sul? A declaração de Azevedo Fortes é muito clara, informando que o arco servia de porta na quinta de Luís Freire da Fonseca Coutinho, na Aramenha, a quinta da Azenha Branca. Esta referência elimina a eventualidade do arco ter sido escavado, em qualquer local da Aramenha, em 1710. Todavia, o silêncio de Frei Amador Arrais 
a propósito de um monumento desta importância, que não deixaria de se destacar num campo de ruínas devastado, como já era o da Ammaia no século XVII, não deixa de ser intrigante e, talvez, significativo.

O grau de destruição das estruturas sobreviventes na zona da Porta Sul é grande, em parte devido às características do nível freático, que desequilibrou e fez abater parte delas, verificando-se ainda confusas reconstruções e adaptações de várias épocas (Pereira 2009: 60-77, 175). Se quisermos manter a Porta Sul de Ammaia como o monumento de onde foi retirado o arco, de acordo com a expressão tirado debaixo das antiguas ruínas, devemos considerar que o arco corresponderia ao lado interior da porta, pois o espaço ainda balizado pelos restos de pilares que aí se vêem mede aproximadamente 3,20 metros de largura (Fig.5). Existiria ainda outra possibilidade, se não fosse a clara atribuição à Azenha Branca. Com efeito, o forum de Ammaia, de excepcionais dimensões, corresponde ao modelo que, entre outros lugares, foi utilizado em Évora, caracterizado pela localização do templo num plano superior, ocupando a basílica o lado oposto da praça. Esta

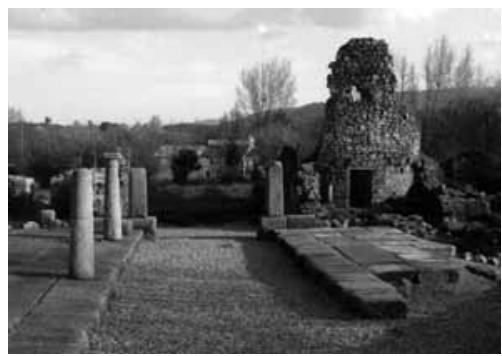

Fig.5. Vista do lado interior das ruínas da Porta Sul (S. Salvador de Aramenha). disposição obriga à existência de uma entrada lateral no monumento, que identificámos na quadrícula A-605 da escavação, na qual subsiste ainda uma aduela. Como, na altura, o referido quadrado se encontrava no limite escavado, não foi possível conhecer a largura da referida porta, que serviria o decumanus delimitando a zona sacra da praça (Mantas 2010: 181-188). A escavação futura desta área permitirá não só reconhecer a implantação completa da porta como verificar a existência de vestígios de trabalhos de recuperação de materiais. Assim, por enquanto, a hipótese do arco ter sido trasladado das ruínas da Porta Sul permanece válida, com as reservas que referimos. Finalmente, para não esquecer nenhuma hipótese plausível, podemos admitir que o arco tivesse sido anteriormente transferido de algum outro local das ruínas de Aramenha para servir de portada à quinta referida no documento de Azevedo Fortes.

Atendendo à complexidade de um problema que parecia definitivamente resolvido referimos o que nos parece mais significativo para uma melhor compreensão do mesmo. Duvidar da notícia transmitida pelo texto da inscrição da porta ou da certidão que transcrevemos não nos parece o 
melhor caminho para resolver a questão, desde logo considerando a personalidade do governador e a responsabilidade envolvida numa declaração ajuramentada e noutra afixada publicamente. Quanto a nós, o documento verdadeiramente decisivo quanto à transferência do arco é a certidão de Azevedo Fortes, justificando as vantagens da reutilização do arco na porta a construir em Castelo de Vide. A Porta da Aramenha foi levantada na cortina de S. Francisco, um pouco a sul do Forte de S. Roque, dando saída para Marvão e Aramenha (Fig.6). Era precedida no exterior por um passadiço entre altos parapeitos, dominado pela guarita que sobrepujava a porta. Sem

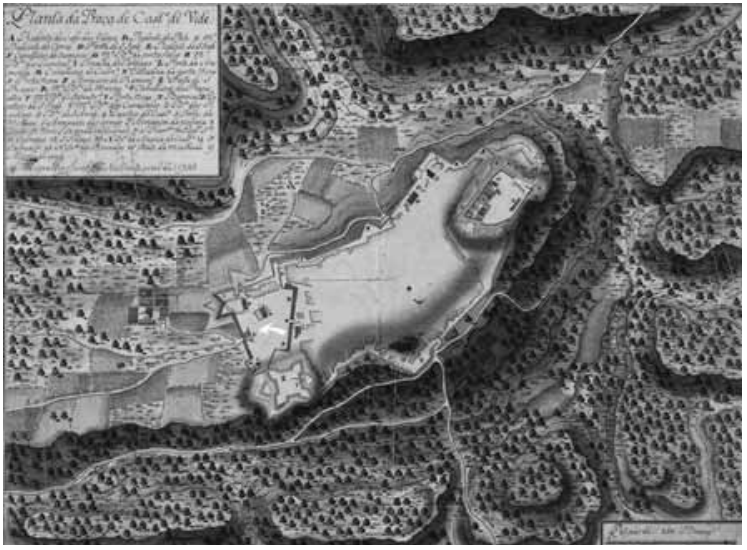

Fig.6. Planta da Praça de Castelo de Vide em 1755 (DIE). A seta indica a Porta da Aramenha.

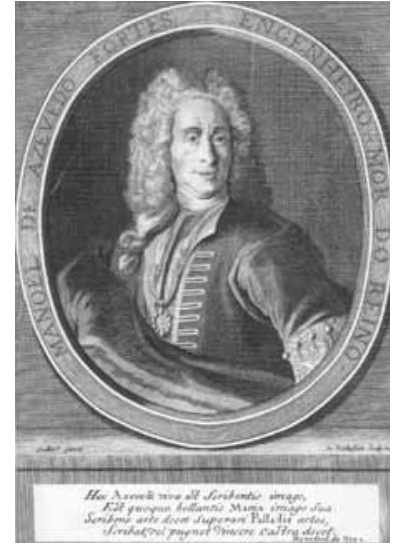

Fig.7. Manuel de Azevedo Fortes (Gravura de Massar de Rochefort. Colecção da Sociedade Martins Sarmento, Guimarães).

ostentar a riqueza ornamental de outras portadas, não deixava de constituir um bom exemplo da arquitectura militar barroca, com alguma tendência para o neoclassicismo que marcará o final do século XVIII.

Construída no contexto da Guerra da Sucessão de Espanha, que decorreu com altos e baixos em relação aos interesses portugueses, mas que teve exactamente na área fronteiriça do Alto Alentejo um dos seus cenários peninsulares mais activos (Monteiro 2004: 301-306; Videira 2008: 55), a Porta da Aramenha integra-se no grande esforço de remodelação das fortalezas fronteiriças, no qual participou activamente o notável engenheiro militar Manuel de Azevedo Fortes (Fig.7). Este foi uma figura típica de estrangeirado, um homem das luzes com excelente formação nalgumas das áreas em que o nosso país era então reconhecidamente deficitário, 
como a cartografia, a matemática, a engenharia e a fortificação moderna, na linha do francês Vauban. Autor de importantes obras publicadas, como O Engenheiro Português e Lógica Racional Geométrica e Analítica (Fortes 1728-1729; 1744), foi professor na Universidade de Siena e integrou a Academia Real da História desde a sua fundação em 1721. Introdutor do cartesianismo em Portugal, alcançou o título de Engenheiro-Mor do Reino em 1719, possuindo um perfil científico e um comportamento social que não poderia deixar de chamar a atenção a um monarca instruído, como foi o Rei Magnânimo. Governador da praça de Castelo de Vide, entre 1709 e 1715, foi no início desde mandato que promoveu a deslocação e reutilização do arco da Aramenha. Não estamos, portanto, a evocar uma figura obscura, muito pelo contrário, trata-se de uma das grandes figuras setecentistas portuguesas (Bernardo 2005; AA.VV. 2006; Diogo / Matos 2007: 125-146).

Existem diversas plantas das fortificações da vila alentejana, delineadas no século XVIII, onde a Porta da Aramenha se encontra perfeitamente localizada (Jacob 1755; Raigado 1773; Homem 1780 ?) ${ }^{7}$, situando-se o monumento na extremidade do que é actualmente a Avenida da Aramenha, na zona adjacente à unidade hoteleira que sucedeu ao desaparecido Asilo da Infância Desvalida, cujo edifício foi em parte construído com materiais provenientes da demolição da Porta da Aramenha (Fig.8), incluindo as aduelas do arco, que teriam sido reutilizadas nas fundações. Não nos interessa, de momento, desenvolver a história da destruição do arco (Videira 2008: 58, 157, 208; Coelho, 1988: 65-67, 398), cuja demolição se iniciou em 2 de Novembro de 1891. Com este acto, tão vulgar no século XIX, nascido de uma imbecil confusão entre progresso e destruição do antigo, como a propósito de situações semelhantes se referiu acerbamente Ramalho Ortigão (Ortigão 1943: 65-99), desapareceu o resultado de uma iniciativa própria de um

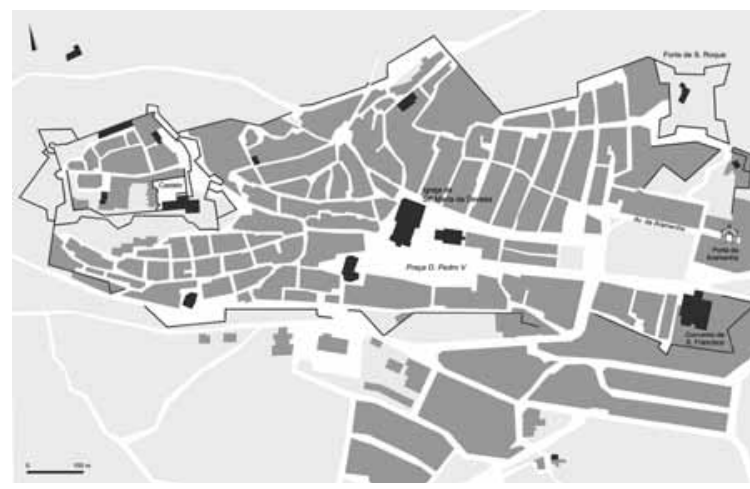

Fig.8. Localização da Porta da Aramenha na planta actual de Castelo de Vide.

7 Em todas estas cartas a Porta da Aramenha se encontra perfeitamente registada. 


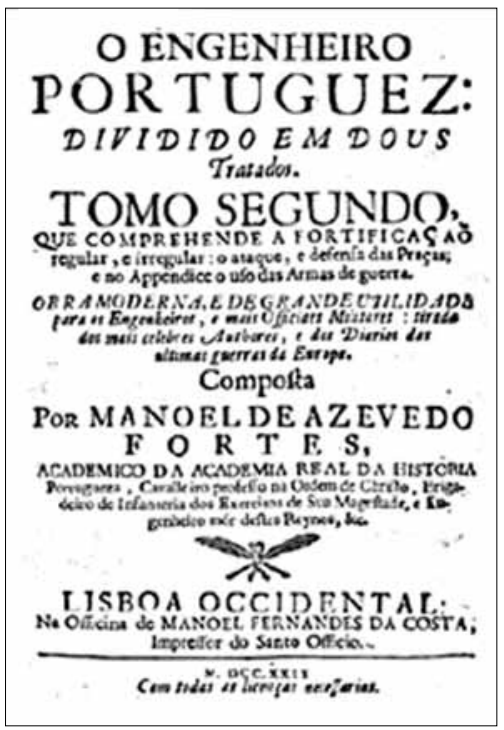

Fig.9. Portada do segundo tomo da obra O Engenheiro Portuguez. espírito ilustrado, que afinal não estava apenas além do seu próprio tempo e da indolência habitual na salvaguarda do património que nos ficou, como o Coronel Dickson não se dispensou de sublinhar cruamente (Leslie 1905: 160), ainda que sem considerar no seu reparo a fúria civilisadora das edilidades referida um século depois por Vergílio Correia (Correia 1972: 224).

O estudo da arqueologia romana do território português, mesmo retomando temas, como este, longe de se encontrarem inéditos, proporciona oportunidades muito interessantes do ponto de vista da pesquisa interdisciplinar e atravessando diferentes períodos históricos. O caso da desaparecida Porta da Aramenha constitui um excelente exemplo da perenidade dos modelos arquitectónicos clássicos, reinterpretados ciclicamente, tanto como forma de afirmar o poder estatal, como em versões de leitura oposta, ou que pretendem sê-lo, como sucedeu com os revolucionários franceses de 1789. O respeito por um grande passado, nomeadamente de natureza militar, aliou-se, no monumento de Castelo de Vide, à vontade de marcar tempos que se pretendiam novos, plenos de racionalidade e de conhecimento (Fig.9), naturalmente ao serviço de um rei que era, então, um César. Serve também, passados três séculos sobre a transferência do arco, numa época em que se agudiza o conflito entre valores e tecnocracia, para sublinhar a necessidade de investigar a fundo o que pode, ou não, ser verdade, tanto quanto esta nos é alcançável, sempre sob o mote Restituet omnia.

\section{Bibliografia}

AA.VV. (2006) in Fernandes, Mário (coord.), Manoel de Azevedo Fortes (16601749). Cartografia, cultura e urbanismo. Porto, Gabinete de Estudos de Desenvolvimento e Ordenamento do Território.

ARraIs, Frei Amador (1974), Diálogos de Frei Amador Arrais (introd. e revisão de M. Lopes de Almeida). Porto, Lello e Irmãos. 
Abascal, J. Manuel / Cebrián, Rosario (2009), Los viajes de José Cornide por España y Portugal de 1754 a 1801. Madrid, Real Academia de la Historia.

Bernardo, Luís M. (2005), O projecto cultural de Manuel de Azevedo Fortes: um caso de recepção do cartesianismo na ilustração portuguesa. Lisboa, Imprensa Nacional-Casa da Moeda.

ChOAY, Françoise (2009, $3^{\mathrm{a}}$ ed.), Alegoria do património. Lisboa, Edições 70.

CorreiA, Vergílio (1972), “Arcos romanos em Portugal”, Obras, IV. Coimbra, Universidade: 223-227.

Coelho, P. Laranjo (1988, 2a ed.), Terras de Odiana. Subsídios para a sua história documentada (rev. e notas de Diamantino Trindade). Lisboa, Câmara Municipal de Castelo de Vide / Câmara Municipal de Marvão.

Diogo, M. P. / Matos, A. C. (2007), "Being an engineer in the European Periphery: three cases studies in Portuguese engineering", History of Technology, 27: 125-146

EsPanCA, Túlio (1969), "Fortificações da cidade de Estremoz”, A Cidade de Évora, 51-52: 65-85.

FARIA, J. M. de (1865), Planta do tranzito da Porta d'Aramanha na praça de Castello de Vide e das casas isoladas que no mesmo existem (cópia de Bon de Souza). 3636-3-36-49 (DSE)-CRT/2003.

Fortes, Manuel de Azevedo (1728-1729), O Engenheiro Portuguez, dividido em Dous Tratados, I-II. Lisboa, Manuel Fernandes da Costa.

Fortes, Manuel de Azevedo (1744), Logica Racional, Geometrica e Analytica. Lisboa, José António Plates.

GuerrA, Amílcar (1996), “Ammaia, Medobriga e as ruínas de S. Salvador de Aramenha. Dos antiquários à historiografia actual”, A Cidade, nova série, 11: 7-33.

GoRJÃo, Sérgio / Machado, J. L. (1993), “O actual concelho de Marvão e as suas freguesias mas Memórias Paroquiais de 1758”, Ibn Maruán, 3: 51-84.

Gusmão, F. Rodrigues (1861), “Apontamentos archeologicos: Porta da Aramenha, Medobriga”, Archivo Pittoresco, IX, 4: 394.

Homem, Lourenço (1780 ?), Praça de Castello de Vide. 3643 / IV-3-36-49 (DSE)CRT / 2003.

JАСОВ, M. Luís (1755), Planta da Praça de Castello de Vide na vezita geral de 1755. 3642 / I-3-36-49 (DSE)-CRT / 2003.

LeSLIE, J. H. (1905), The Dickson Manuscripts. Serie “C” - from 1808 to 1818, II. Woolwich, Royal Artillery Institution. 
Mantas, Vasco (1992), "Notas sobre a estrutura urbana de Aeminium", Biblos, 68: $487-513$.

Mantas, Vasco (2000), “A sociedade luso-romana do município de Ammaia”, in J.-G. Gorges / T. Nogales Basarrate (coords), Sociedad y Cultura en Lusitania Romana. Mérida, Junta de Extremadura: 391-420.

MANTAS, Vasco (2009), “A Lusitânia e os Lusitanos há duzentos anos”, in J.-G. Gorges et alii (eds), Lusitânia Romana Entre o Mito e a Realidade. Cascais: 89-109.

Mantas, Vasco (2010), “Ammaia e Civitas Igaeditanorum. Dois espaços forenses lusitanos", in T. Nogales Basarrate (ed), Ciudad y foro en Lusitania Romana, Mérida, Junta de Extremadura: 167-188.

Monteiro, N. Gonçalo (2004), "A Guerra da Sucessão de Espanha” in M. Themudo Barata / N. Severiano Teixeira (dirs.), Nova História Militar de Portugal, 2. Lisboa, Círculo de Leitores: 301-306.

OliveIRA, J. de (1992) “A ponte quinhentista da Portagem”, Ibn Maruán, 2: 121-130.

OliveIRA, J. de et alii (2005), in Jorge de Oliveira (coord), "S. Salvador de Aramenha. História e memórias da freguesia”, Ibn Maruán, (número especial) 13.

Ortigẽo, Ramalho (1943, 3ª ed.), Arte Portuguesa, I. Lisboa, Livraria Clássica Editora.

PEREIRA, Sérgio (2009), “A cidade romana de Ammaia. Escavações arqueológicas 2000-2006”, Ibn Maruán, (número especial) II.

RAIGAdo (1773), Carta ichnographica da praça de Castello de Vide, situada na provincia do Alentejo. 3643 / III-3-36.49 (DSE)-CRT / 2003.

StYlow, Armin (2009), "O estatuto jurídico de Ammaia. A propósito de uma inscrição copiada em 1810”, Ibn Maruán, (número especial) 16: 35-55.

SilveIrA, Francisco do Nascimento (1804), Mappa breve da Lusitania Antiga e Galliza Bracarense. Lisboa, Simão Tadeu Ferreira.

Sotto Mayor, Diogo Pereira de (1984), Tratado da cidade de Portalegre (introd., leitura e notas de L. C. Martins). Maia, Imprensa Nacional-Casa da Moeda.

VAsconcelos, J. Leite de (1913), Religiões da Lusitânia, III. Lisboa, Imprensa Nacional.

VIDEIRA, César (2008, $3^{\mathrm{a}}$ ed.), Memória histórica da muito notável vila de Castelo de Vide (Ana Patrício et alii coord.). Lisboa, Colibri. 